American Journal of Pharmaceutical Education 2016; 80 (9) Article 151.

\title{
RESEARCH
}

\section{Description and Evaluation of an MPharm Practice-based Experience Pilot Program}

\author{
Philip Winn, SRPharmS, ${ }^{a}$ Christopher J. Turner, PhD, BPharm ${ }^{\mathrm{b}}$ \\ ${ }^{a}$ Strathclyde Institute of Pharmacy and Biomedical Sciences, University of Strathclyde, Glasgow, Scotland \\ ${ }^{\mathrm{b}}$ Skaggs School of Pharmacy and Pharmaceutical Sciences, University of Colorado, Aurora, Colorado \\ Submitted August 18, 2015; accepted December 15, 2015; published November 25, 2016.
}

Objective. To determine the level of support among pharmacists in central Scotland to serve as mentors and provide practice-based experience to students enrolled in a master of pharmacy degree program.

Methods. A study was conducted during the 2011-2012 academic year in which first-year MPharm students in Scotland were paired with practicing pharmacists for 2 half-day visits per month. The students were integrated into the pharmacy workflow and engaged in activities ranging from date checking to counseling patients. The pharmacists and students who participated were asked to complete a survey in spring 2012 regarding their experiences and, in addition, the students were asked to maintain diary entries describing their experiences.

Results. Thirty-nine students were paired successfully with 38 pharmacists. Every pharmacist stated their student was welcome to return in the 2012-2013 academic year and 29 agreed to accept a second student. Nine of 12 participating chain community pharmacies asked for program expansion and 11 chain community pharmacies and one other community pharmacy that did not participate in 2011-2012 asked to join in 2012-2013.

Conclusion. Large numbers of pharmacists in central Scotland are willing to mentor and provide practice-based pharmacy education for students in a manner consistent with General Pharmaceutical Council accreditation standards for the master of pharmacy degree curriculum.

Keywords: MPharm degree program, pharmacy students, accreditation standards, experiential education, practice-based education, preceptors

\section{INTRODUCTION}

Pharmacy education in the United Kingdom is undergoing substantial changes, particularly with respect to practical (work-based) experience for pharmacy students. ${ }^{1,2}$ The 2011 General Pharmaceutical Council (GPhC) introduced accreditation standards for the entry-to-practice master of pharmacy (MPharm) degree program requiring students to gain practical experience in working with patients, carers and health care professionals, with the amount of time the student spent in these activities increasing with each year of the program. ${ }^{1}$ Concomitantly, the Modernising Pharmacy Careers Professional Board published a proposal to integrate undergraduate and preregistration training into a 5-year curriculum jointly owned, planned, and delivered by universities and employers with emphasis on work-based learning and contact with patients from earlier in the degree program. ${ }^{2}$

Corresponding Author: Christopher J. Turner, 21811 East

Berry Lane, Centennial, CO 80015. Tel: 720-870-9599.

E-mail: Christopher.Turner@ucdenver.edu
The requirement for pharmacy students to engage in work-based learning with patient contact early in their degree program was introduced in the United States in 1997 by the Accreditation Council for Pharmacy Education as part of the transition to the entry-to-practice doctor of pharmacy (PharmD) degree program. ${ }^{3}$ The University of Colorado Skaggs School of Pharmacy and Pharmaceutical Sciences (SSPPS) implemented its entry-to-practice PharmD program in 1999 and, as part of that program, chose to integrate practical experiences in all 6 semesters that comprise the first 3 years of the school's 4-year PharmD program (the fourth year of the program equates to the preregistration year in the United Kingdom). The primary features of the SSPPS practical experience courses, which were designed in collaboration with the practice community, were the integration of students into the pharmacy workforce on a continuous halfday per week basis and the establishment of long-term mentor-mentee relationships between students and pharmacists and other healthcare practitioners. Descriptions and evaluations of those courses have been published. ${ }^{4-8}$ 


\section{American Journal of Pharmaceutical Education 2016; 80 (9) Article 151.}

In this paper, we describe and evaluate a pilot MPharm practical experience program in the Strathclyde Institute of Pharmacy and Biomedical Sciences (SIPBS) in Glasgow, Scotland, based on the model employed by SSPPS. The primary goal of the study was to provide guidance to SIPBS for the inclusion of practical experiences in its MPharm degree program. The primary objective was to gauge the support of the pharmacy practice community in central Scotland for providing practical experiences for students in the MPharm program. The study constituted a sabbatical project for one author (CJT), comprised of a full-time year (2011-2012) and four 2-week visits to Scotland in 2012-2013.

\section{METHODS}

Volunteer community and hospital pharmacists in central Scotland were paired with volunteer first-year MPharm students during the 2011-2012 academic year. The purpose of the study was explained to the class by the investigators in a face-to-face meeting at the start of the year. The students were asked to volunteer for two 3-hour practice site visits per month as a cocurricular activity. Volunteers were told that they would complete activities chosen by their pharmacist mentor (the term used in the US is preceptor, which better captures the teaching relationship over and above the coaching that a mentor might deliver); submit diary entries after each visit; complete a questionnaire about their experiences at the end of the academic year; be free to ask questions and to withdraw from the pilot program at any time without penalty; and be reimbursed for their travel expenses but not be paid for their work. Students who chose to volunteer were asked for their preferences with respect to practice site location and type (community or hospital pharmacy or no preference).

Two methods were used to recruit community and hospital pharmacists to participate in the program. Meetings were sought with National Health Service (NHS) board pharmacy administrators, owners of community pharmacies, and district/regional managers of national community pharmacy companies with established contacts with SIPBS. The purpose of the meetings was to describe the purpose and the details of the pilot project, request permission to approach individual pharmacists, and ask for suggestions for pharmacists to approach. Community pharmacists with no established contact with SIPBS were approached through Community Pharmacy Scotland (CPS). The CPS board of directors supported the pilot program and disseminated information to its membership about the program and contact information for the investigators. Permission to make a site visit was sought from CPS members who contacted the investigators. Site visits were used to discuss the pilot program within the context of the 2011 GPhC MPharm accreditation standards.

Community and hospital pharmacists were asked to be a preceptor for one first-year MPharm student for two 3-hour visits per month during the academic year, with the day and time of individual visits to be arranged with the student. They were asked to integrate their student into the pharmacy workflow; establish a mentor-mentee relationship with their student to support learning; use their best judgment to give their student a steadily increasing breadth and depth of workplace experiences; and not pay students for their work. The volunteer preceptors were told that they were free to ask questions, were free to withdraw from the pilot program at any time, and would be asked to complete a questionnaire at the end of the academic year. Given that the primary goal of the study was to provide guidance to SIPBS, the preceptors were deliberately left to decide for themselves what activities they thought appropriate for the students.

Recruitment of community pharmacists was halted when all students who requested a community pharmacy placement were paired with a community pharmacist. Hospital pharmacy preceptors were recruited and students were paired with them throughout the 2011-2012 academic year. The investigators' strategy was to involve as many different hospitals and community pharmacy companies as possible. The student/pharmacist pairings constituted demonstration projects for the participating hospitals and community pharmacy companies and those participants were contacted at the end of the 2011-2012 academic year to determine their interest in expanding the study in the 2012-2013 academic year. Those wishing expansion were asked for the names and contact information of other pharmacists to approach. In addition, community pharmacies in central Scotland that did not participate in 2011-2012 were contacted to determine their interest in participating in 2012-2013 and for suggestions for other pharmacists to contact.

A concomitant study was conducted to validate and complement the findings of this study. Researchers from the School of Psychological Sciences and Health, University of Strathclyde, were contracted to undertake an independent qualitative evaluation of the project based on one-on-one confidential interviews with volunteer pharmacists and students. The results of that qualitative evaluation will be published separately.

\section{RESULTS}

Information on the numbers of students, NHS boards, community pharmacy companies and community and hospital pharmacists who participated in the 2011-2012 project is presented in Table 1. Sixty-five of $154(42 \%)$ students in 


\section{American Journal of Pharmaceutical Education 2016; 80 (9) Article 151.}

Table 1. Participants in a Study to Determine the Willingness of Pharmacists in Central Scotland to Serve as Mentors for Students Enrolled in a Master of Pharmacy Degree Program

\begin{tabular}{lc}
\hline Group & Participants \\
\hline First-year MPharm class & 154 \\
$\quad$ Class size, No. & $65(42)$ \\
$\quad$ Student Volunteers, No. (\%) & 6 \\
National Health Service Boards & $4(66)$ \\
$\quad$ Asked to participate, No. & \\
$\quad$ Gave permission to contact & \\
$\quad$ pharmacists, No. (\%) & 18 \\
Community pharmacy companies & $18(100)$ \\
$\quad$ Asked to participate, No. & \\
$\quad$ Gave permission to contact & \\
$\quad$ pharmacists, No. (\%) & 29 \\
Community pharmacists & $29(100)$ \\
$\quad$ Asked to participate, No. & \\
Agreed to participate, No. (\%) & 11 \\
Hospital pharmacists & $9(82)$ \\
$\quad$ Asked to participate, No. & \\
Agreed to participate, No. (\%)
\end{tabular}

the 2011-2012 first-year SIPBS MPharm class volunteered for the pilot program. By the end of the 2011-2012 academic-year, 39 students were paired with 29 community pharmacists and nine hospital pharmacists (one community pharmacist supervised two students). The recruitment of community pharmacists was much easier and faster than hospital pharmacists. All students who expressed interest in community pharmacy practice were paired with a community pharmacist within a few months, but by the end of the 2011-2012 academic year, the recruitment of hospital pharmacists was insufficient to accommodate all the students who requested a hospital placement.

All the NHS board representatives who were interviewed expressed interest in the pilot program; however, some expressed concerns over what they perceived as adding to pharmacists' workload. The number of student visits reported by the participating pharmacists at the end of the 2011-2012 academic year is shown in Figure 1. The average number of visits for hospital-based students (not shown) was limited in comparison to community pharmacy-based students by the time needed to meet site administrative requirements including Disclosure Scotland certification. Some student/hospital preceptor pairs, particularly those distant from SIPBS, chose to complete visits after the end of the academic year (ie, during the summer vacation period).

Table 2 presents information on the NHS boards, community pharmacy companies and community and hospital pharmacists interviewed after the end of the 2011-2012 academic year. Every pharmacist who mentored a student in 2011-2012 stated that their student would be welcome

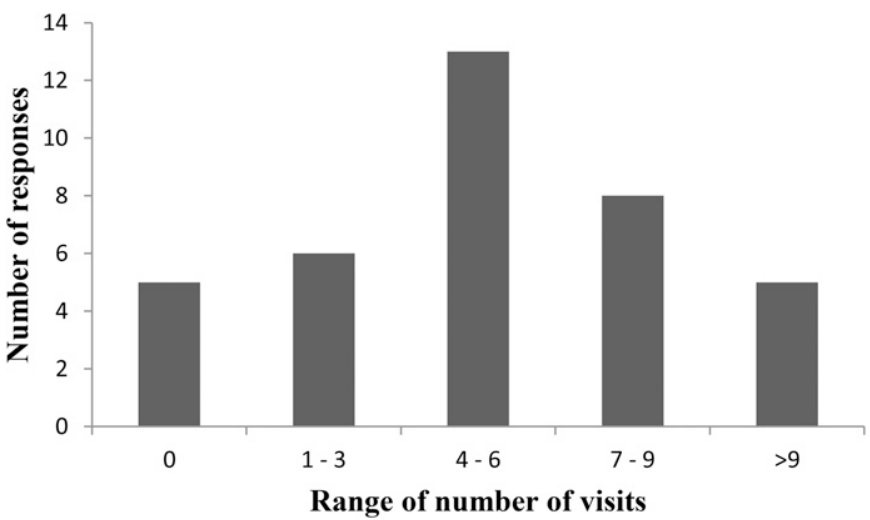

Figure 1. Number of Practice Site Visits Accumulated by Individual Students in the 2011-12 Academic Year.

back for two 3-hour visits per month for another year (2012-2013) and three-fourths stated they were willing to accept a new first-year student in addition to welcoming their returning student. Most stipulated that the 2 students should not be at the site on the same day and time for logistical reasons. All NHS boards and all but one community pharmacy company stated they were willing to continue the pilot project for a second year. Nine of 12 participating regional and national chain community pharmacy companies asked for program expansion and 12 community pharmacy companies that did not participate in 2011-2012 asked to join the program for 2012-2013.

The community pharmacies wishing to expand their involvement in or join the pilot program in 2012-2013 gave contact information for multiple pharmacies and, in the time available to the investigators, 89 pharmacists who did not participate in 2011-2012 were interviewed. All but one agreed to mentor MPharm students for a year-long series of two 3-hour visits per month and, collectively, offered places for 167 students (Table 2). The students who volunteered for the pilot program requested practice sites in the areas served by NHS Ayrshire and Arran, NHS Borders, NHS Forth Valley, NHS Greater Glasgow and Clyde, NHS Lanarkshire and NHS Lothian. The community pharmacists interviewed represented $14 \%$ of the community pharmacies in those geographic areas.

Twenty-three students submitted 137 diary entries describing individual practice site visits. In $61 \%, 56 \%$, and $54 \%$ of the diary entries, the students reported that the visit reinforced previous learning, the visit provided new learning, and the activities undertaken were useful to the practice site, respectively. The students' diary entries were collated to establish the range of tasks and responsibilities that their preceptors assigned to them during the course of the 2011-2012 academic year (Table 3). The diary entries showed that the students were given a broad variety of tasks and responsibilities ranging from simple (eg, expiry date 


\section{American Journal of Pharmaceutical Education 2016; 80 (9) Article 151.}

Table 2. 2012-13 Participation by NHS Boards, Community Pharmacy Companies and Community and Hospital Pharmacists

\begin{tabular}{|c|c|}
\hline Group & Participants \\
\hline \multicolumn{2}{|l|}{ Community pharmacists } \\
\hline Asked at the end of the 2011-12 academic year if student welcome to return for a second year, No. & 29 \\
\hline Agreed to the above request, No. (\%) & $29(100)$ \\
\hline $\begin{array}{l}\text { Asked at the end of the } 2011-12 \text { academic year if willing to host a new } 1^{\text {st }} \text { year student in addition to } \\
2^{\text {nd }} \text { year student returning from } 2011-12 \text {, No. }\end{array}$ & 29 \\
\hline Agreed to the above request, No. (\%) & $24(83)$ \\
\hline $\begin{array}{l}\text { Pharmacists who did not participate in } 2011-12 \text { asked in } 2012-13 \text { if willing to host a } 1^{\text {st }} \text { year pharmacy } \\
\text { student, No. }\end{array}$ & 89 \\
\hline Agreed to the above request, No. (\%) & $88(99 \%)$ \\
\hline $\begin{array}{l}\text { Pharmacists who did not participate in } 2011-12 \text { asked in } 2012-13 \text { if willing to host a } 2^{\text {nd }} \text { year pharmacy } \\
\text { student in addition to hosting a } 1^{\text {st }} \text { year pharmacy student, No. }\end{array}$ & 89 \\
\hline Agreed to the above request, No. (\%) & $79(89 \%)$ \\
\hline \multicolumn{2}{|l|}{ Hospital pharmacists } \\
\hline Asked at the end of the 2011-12 academic year if student welcome to return for a second year, No. & 9 \\
\hline Agreed to the above request, No. (\%) & $9(100)$ \\
\hline $\begin{array}{l}\text { Asked at the end of the } 2011-12 \text { academic year if willing to host a new } 1^{\text {st }} \text { year student in addition to } \\
2^{\text {nd }} \text { year student returning from } 2011-12 \text {, No. }\end{array}$ & 9 \\
\hline Agreed to the above request, No. $(\%)$ & $5(56 \%)$ \\
\hline \multicolumn{2}{|l|}{ NHS Boards } \\
\hline 2011-12 participants asked to expand participation, No. & 4 \\
\hline Agreed to the above request, No. (\%) & $3(75)$ \\
\hline \multicolumn{2}{|l|}{ Chain community pharmacy companies } \\
\hline 2011-12 participants asked to expand participation, No & 12 \\
\hline Agreed to the above request, No. $(\%)$ & $9(75)$ \\
\hline New entities asked to participate in $2012-13$, No & $13^{*}$ \\
\hline Agreed to the above request, No. $(\%)$ & $12(92)^{*}$ \\
\hline
\end{tabular}

*includes 1 non-chain pharmacy

checking) to complex tasks (eg, patient counseling). Other results from the students' diary entries will be published separately.

Thirty-one of 38 preceptors surveyed at the end of the 2011-2012 academic year submitted responses (81\% response rate). Eighty-one percent of them strongly agreed or agreed that it is important for students to have practicebased experiences as a core (required) element in their first-year MPharm program. Eighty-one percent of preceptors also indicated that the optimum length of a practice site visit by a first-year MPharm student was either 3 or 4 hours. All but one preceptor (37/38) stated they would encourage other pharmacists to host a year-long series of half-day visits by a first-year MPharm student. The preceptors' opinions regarding the optimum number of practice site visits are shown in Figure 2. Community pharmacists in comparison to hospital pharmacists preferred more frequent visits ( $60 \%$ of community pharmacists preferred weekly or twice monthly visits).

The preceptors' responses to other survey questions are presented in Table 4. Preceptors reported that they derived self-satisfaction from mentoring/supervising students; the visits were beneficial to the students' education; the students were keen to learn and responsive to constructive feedback; the students gained experience in interacting with patients; and the students were successful over the course of their visits in accepting greater responsibilities and undertaking more difficult tasks. They reported they were confident that first-year MPharm students could be successfully integrated into normal pharmacy workflow. Sixty percent of preceptors reported that their student always visited on the same day of the week and at the same time of day, while the other $40 \%$ reported that their students visited on different days of the week and different times of the day.

Twenty-four of 39 students (61\%) surveyed at the end of 2011-2012 academic-year submitted responses. The most likely explanation for the lower student response rate compared with the $81 \%$ preceptor response rate was that the students were focused on preparing for end-of-year MPharm examinations rather than on voluntary participation in a research study. Ninety-two percent of the students who submitted responses strongly agreed or agreed that it was important for students to have practice-based experiences as a core (required) element in their first-year MPharm program (5-point scale: strongly agree, agree, neutral, disagree, strongly disagree). Eighty 


\section{American Journal of Pharmaceutical Education 2016; 80 (9) Article 151.}

Table 3. Information Abstracted from Students' Diaries

\begin{tabular}{|c|c|}
\hline Orientation & $\begin{array}{l}\text { Read and signed "Standard Operating Procedure" documents: } \\
\text { introduced to pharmacy staff. }\end{array}$ \\
\hline Dispensing Process & $\begin{array}{l}\text { Greeted patients and received prescriptions: checked prescription orders for legal } \\
\text { compliance: reviewed patients' medical and medication histories and laboratory results: } \\
\text { checked for drug interactions: scanned prescription barcodes: generated prescription labels: } \\
\text { selected medicine from stock shelves: counted/measured medications: reconstituted } \\
\text { medications: packaged and labeled prescriptions: filled "Dosset" boxes: prepared "owed" } \\
\text { medications: signed prescriptions (as appropriate to document role in dispensing process): } \\
\text { selected information pamphlets for inclusion with dispensed medication: handed off work for } \\
\text { technician and pharmacist checking: stored prescriptions for collection by patient: handed out } \\
\text { prescriptions to patients: dispensed private prescriptions. }\end{array}$ \\
\hline Stock control & $\begin{array}{l}\text { Ordered medicines from suppliers: reconciled deliveries of medications with invoices: shelved } \\
\text { new stock: filed invoices: re-shelved bulk stock after completion of dispensing process: } \\
\text { priced and shelved self-care products: date checked stock: completed controlled drug counts: } \\
\text { wrote entries in controlled drug register: destroyed controlled drugs. }\end{array}$ \\
\hline Specific learning activities & $\begin{array}{l}\text { Learned range of formulations in which medications are manufactured: operation of medication } \\
\text { administration devices (e.g. metered-dose inhalers): range of pharmacy services (e.g. smoking } \\
\text { cessation service): drug information resources: pharmacy abbreviations: accounting procedures: } \\
\text { aseptic techniques: mathematical calculations. }\end{array}$ \\
\hline
\end{tabular}

percent stated that the optimum length of a practice site visit by a first-year MPharm student was 3 or 4 hours. The students expressed a clear preference for two visits per month (Figure 2). All the respondents stated that they would encourage other first-year MPharm students to undertake a year-long series of half-day practice site visits.

The students' responses to other survey questions are presented in Table 5. Those responses provide evidence that the students derived satisfaction from their practice site activities. They believed their experiences were valuable to their education and that they were successfully integrated into the practice site workflow. They reported increases in their confidence to practice pharmacy, in their pharmacy practice knowledge, and in their ability to accept greater responsibilities and undertake difficult tasks. They reported greater progress in developing their ability to interact with practice site

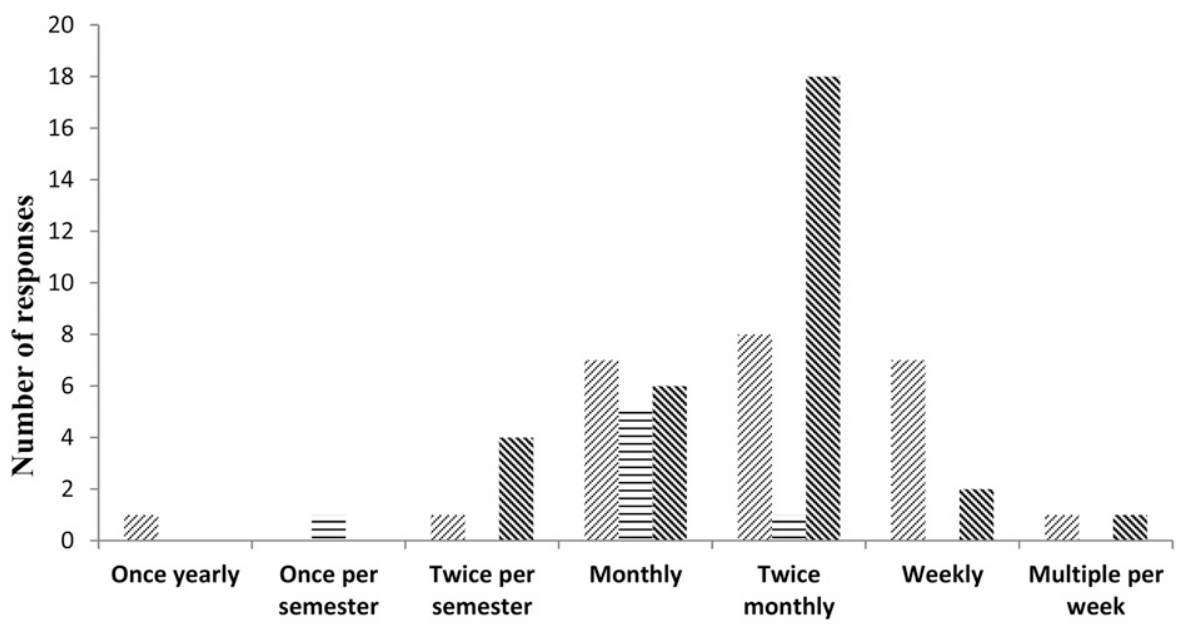

\% Community pharmacist

$\equiv$ Hospital pharmacist

student

Figure 2. Preceptor and Student Preferences for Frequency of Practice Site Visits 


\section{American Journal of Pharmaceutical Education 2016; 80 (9) Article 151.}

Table 4. Pharmacists' Opinions Regarding their Involvement in the Project and their Assessment of Student Performance*

\begin{tabular}{l}
\hline Level of self-satisfaction derived from mentoring a student $(1=$ no satisfaction \\
and $10=$ great satisfaction). \\
Value of visits in terms of student's pharmacy education $(1=$ no value and $10=$ great value). \\
Progress made by the student over the course of her/his practice site visits in undertaking increasingly \\
$\quad$ difficult tasks. \\
Progress made by the student in her/his ability to accept greater responsibilities. \\
Progress made by the student in developing her/his self-confidence to practice pharmacy. \\
Progress made by the student in developing her/his ability to interact with patients. \\
Progress made by the student in developing her/his pharmacy practice knowledge (e.g. drug names and \\
$\quad$ indications). \\
Students commitment to learning $(1=$ no commitment and $10=$ great commitment). \\
Students responsiveness to constructive feedback $(1=$ not responsive and $10=$ very responsive). \\
Level of confidence that a $1^{\text {st }}$-year MPharm student can be successfully integrated in normal pharmacy workflow \\
$\quad(1=$ no confidence and $10=$ great confidence).
\end{tabular}

$\mathrm{N}=31$

*Responses were assessed on a 10-point scale where, unless otherwise stated, $1=$ no progress and $10=$ substantial progress over the course of the student's practice site visits

employees than with patients and members of the public. They reported that the preceptors were committed to the students' education and provided valuable mentoring.

\section{DISCUSSION}

The results of this study demonstrate a successful collaboration between a US university and a Scottish university regarding the education of pharmacy students. The societal pressure for pharmacists to play a greater role in disease prevention, health promotion, and the safe, effective, and economical use of medications is international in nature. In responding to that pressure, it is important for pharmacy colleges and schools to collaborate not only locally and nationally but also internationally in the education of pharmacy students, regardless of the differences in health care systems between countries.

The results provide guidance for the integration of pharmacy practice-based experiences in the MPharm curriculum. The results also demonstrate that large numbers

Table 5. Students' Opinions Regarding their Involvement in the Project and their Self-Assessment of their Performance*

Level of self-satisfaction derived from practice site activities $(1=$ no satisfaction

Mean (SD) and $10=$ great satisfaction).

Value of visits in terms of student's pharmacy education $(1=$ no value and $10=$ great value $)$.

$8.0(2.0)$

Progress made by the student over the course of her/his practice site visits in undertaking increasingly difficult tasks.

Progress made by the student in her/his ability to accept greater responsibilities.

Progress made by the student in developing her/his self-confidence to practice pharmacy.

Progress made by the student in developing her/his ability to interact with patients.

Progress made by the student in developing her/his ability to interact with practice site employees/personnel.

Progress made by the student in developing her/his pharmacy practice knowledge

(e.g. drug names and indications).

Level of preceptor's commitment to student learning $(1=$ no commitment and

10 = great commitment).

Value of the feedback given by preceptor $(1=$ no value and $10=$ great value $)$.

Level of confidence that student was successfully integrated in normal pharmacy workflow $(1=$ no confidence and $10=$ great confidence $)$.

$\mathrm{N}=4$

*Responses were assessed on a 10-point scale where, unless otherwise stated, $1=$ no progress and $10=$ substantial progress over the course of the student's practice site visits 


\section{American Journal of Pharmaceutical Education 2016; 80 (9) Article 151.}

of community pharmacists in central Scotland are willing to support practice-based MPharm education if they are allowed to establish one-to-one mentor-mentee relationships with students and if students are integrated into the pharmacy workflow over a year-long series of half-day visits with flexibility to schedule the visits on different days of the week and at different times of day. The results demonstrate the range of experiences preceptors chose (ie, thought appropriate) for first-year MPharm students. Finally, the results demonstrate that MPharm students appreciate the importance of practice-based experience.

The findings from this pilot program are consistent with those in the published literature, ie, that practicebased education is mutually beneficial to students and pharmacy practitioners. ${ }^{9,10}$ This consistency in findings suggests that the SIPBS results are likely to be generalizable across the United Kingdom.

If students are to be competent to fulfill the responsibilities of a pharmacist at the time they become licensed pharmacists, they must be given practice site responsibilities during their training. Similarly, any practice site responsibility given to students must contribute to the achievements of the practice site. Skrabal and colleagues state that "the expectation that student pharmacists can and do contribute to a pharmacy practice site underscores the return on investment of time for the preceptors and sites, and this has become a standard philosophy among many schools today." 9 The expectation is further supported by the community pharmacists' preference for frequent practice site visits. Frequent visits give students the opportunity to hone existing knowledge and skills and to apply new knowledge and skills.

Frequent practice site visits permit experiential education to function on a mentor-mentee level. The survey data and the willingness of the preceptors to accept their students for a second year provide evidence that the preceptors formed long-term mentor-mentee relationships with their students and were invested in their education. Long-term mentor-mentee relationships are sustained if preceptors derive personal satisfaction from seeing their students develop as pharmacy practitioners and if students see that their preceptors are committed to their education.

The practical caveat for any university has to be the difference in scale between what was achieved in a pilot project and what would be required from both the university and pharmacy practitioners to deliver this form of learning over a 4-year degree program. Nevertheless, it is an important indicator of engagement by the profession with education that 126 separate pharmacies intimated that well over 200 placements were available, even though the investigators (in the time available to them) were able to visit only $14 \%$ of the community pharmacies in the six NHS regions closest to SIPBS. Given the GPhC accreditation requirement to organize practice-based experiences that build year-on-year, logistics dictate that there will not be enough practice sites to host all of any university's MPharm students on a one-student-per-practice site model. However, if there is a personal and workforce advantage to hosting one student, then it can be argued that there is a greater advantage to hosting multiple students.

Several practical issues need further discussion. First, preceptors prefer to have the flexibility to change the day and/or time of students' practice site visits from week to week. To accommodate this, ideally students would have multiple windows in their weekly schedules when they could complete practice site visits and communicate with their preceptor about which timeslot was best. Second, based on 16 years of experience as a Director of Experiential Programs (CJT), practice-based education is more successful if students are paired with pharmacists close to the university or to their homes so that students will not spend an inordinate amount of time commuting. A full discussion of logistical issues associated with practice-based learning is beyond the scope of this paper, but it is worth noting that there is existing infrastructure in the United Kingdom to support such a program. ${ }^{11,12}$ NHS Education for Scotland matches MPharm graduates with community and hospital pre-registration places and the Pharmalife scheme in England and Wales matches MPharm graduates with hospital preregistration places. ${ }^{11,12}$ Pharmacy schools in the United States have cooperated at the national and regional level in multiple ways. For example, the American Association of Colleges of Pharmacy offers the PharmCAS program at the national level to coordinate the pharmacy school admission process, and regional groups of schools have collaborated to streamline administrative aspects of practical experience programs and to provide preceptor development. ${ }^{13-15}$

A curriculum that is both science and practice-based provides timetabling challenges, but those challenges are routinely met by US colleges and schools of pharmacy. The results are consistent with the published literature that students can successfully undertake early practice experiences well before they have established an extensive schooltaught knowledge base. ${ }^{16}$ Learning to apply knowledge and skills in practice settings is far more difficult than acquiring knowledge and skills. Thus, students need to have continuous practice-based exposure throughout their pharmacy education. Nonetheless, setting reasonable expectations is important, and the results of this study demonstrate what practitioners in central Scotland believe to be reasonable expectations for first-year MPharm students.

Expiry date checking and filling "Dosset" boxes are appropriate activities for MPharm students at the start of 


\section{American Journal of Pharmaceutical Education 2016; 80 (9) Article 151.}

their first-year given that most will be nervous and need time to become socialized to the pharmacy practice environment. Following standard operating procedures, having students take in prescriptions and hand over dispensed medications are appropriate ways for them to gain experience interacting with patients. Ordering medications from suppliers and reconciling invoices are appropriate ways for students to gain their first experience with the business side of pharmacy. Reconstituting antibiotic suspensions is an appropriate way for students to gain their first experience in preparing medications. Immersion in the dispensing process is appropriate for first-year MPharm students.

The GPhC MPharm accreditation standards dictate that practice experiences must build year-on-year. ${ }^{1}$ Accordingly, it will be important to determine what practitioners believe to be reasonable expectations not only for first-year MPharm students but also for all other years in the MPharm program with and without an integrated preregistration year. Given the proven ability of US PharmD students to accept patient care responsibilities, ${ }^{8,17-21}$ MPharm students also should have practice-based experience in counseling patients with respect to health promotion and disease prevention activities (eg, smoking cessation) and prescription and nonprescription medications (including the NHS minor ailment and chronic medication services). ${ }^{22-24}$ Students will be more and more welcome in the practice environment if their usefulness and productivity increases throughout the MPharm program. Accordingly, pharmacy schools must integrate other elements of the MPharm curriculum with practice-based experiences such that students have continuously increasing knowledge and skill appropriate for their year in the MPharm program which they can apply in pharmacy practice settings.

\section{CONCLUSION}

The study represents a successful international collaboration between two universities regarding entry-to-pharmacy practice curriculum design. The results demonstrate that pharmacy students and pharmacy practitioners in central Scotland see value in practice-based education throughout the MPharm curriculum and that large numbers of community pharmacists are willing to host students at their practice sites in long-term mentormentee relationships. The results provide guidance regarding the design and integration of practice-based experience courses in the MPharm curriculum.

\section{ACKNOWLEDGMENTS}

This work was made possible with the help and encouragement of multiple individuals and health care entities. The authors, in particular, wish to thank the students and pharmacists who participated in the pilot project; Professor
Graham Coombs who was SIPBS Head of Institute when the project was first conceived; Niall Coggans, Simon Mackay and Anne Boyter who were SIPBS Head of the MPharm Programme during the pilot project; Professor Norman Lannigan, NHS Greater Glasgow and Clyde; Community Pharmacy Scotland; NHS Education for Scotland; and the National Pharmacy Association. The study was supported by the University of Strathclyde Education Excellence Fund.

\section{REFERENCES}

1. General Pharmaceutical Council. Future pharmacists: standards for the initial education and training of pharmacists May 2011. http:// www.pharmacyregulation.org/sites/default/files/Standards $\% 20$ for $\%$ 20the $\% 20$ initial $\% 20$ education $\% 20$ and $\% 20$ training $\% 20$ of $\%$ 20pharmacists.pdf.

2. Smith A, Darracott R. Modernizing pharmacy careers programme: review of pharmacist undergraduate training and proposals for reform. https://www.hee.nhs.uk/sites/default/files/documents/ Pharmacist-pre-registration-training-proposals-for-reform.pdf. 3. Accreditation Council for Pharmacy Education. Accreditation standards and guidelines for the professional program in pharmacy leading to the doctor of pharmacy degree. Standards 2016. https:// www.acpe-accredit.org/pdf/Standards2016FINAL.pdf.

4. Turner CJ, Jarvis C, Altiere R, Clark L. A patient focused and outcomes-based experiential course for first year pharmacy students. Am J Pharm Educ. 2000;64(3):312-319.

5. Turner CJ, Altiere R, Clark L, Dwinnell B, Barton AJ. An interdisciplinary introductory pharmacy practice experience course. Am J Pharm Educ. 2004;68(1):Article 10.

6. Jarvis C, James VL, Giles J, Turner CJ. Nutrition and nurturing: a service-learning nutrition pharmacy course. Am J Pharm Educ. 2004;68(2):Article 43.

7. Turner CJ, Altiere R, Clark L, Maffeo C, Valdez C. Competencybased introductory pharmacy practice experiential courses. Am J Pharm Educ. 2005;69(2):Article 21.

8. Turner CJ, Ellis S, Giles J, et al. An introductory pharmacy practice experience emphasizing student-administered vaccinations. Am J Pharm Educ. 2007;71(1):Article 3.

9. Skrabal MZ, Kahaleh AA, Nemire RE, et al. Preceptors' perspectives on benefits of precepting student pharmacists to students, preceptors and the profession. J Am Pharm Assoc. 2006;46(5):605-612. 10. American Journal of Health-System Pharmacy, et al. Capacity of hospitals to partner with academia to meet experiential education requirements for pharmacy students. Am J Pharm Educ. 2008;72(5): Article 117.

11. NHS Education for Scotland. Preregistration Pharmacist Scheme. http://www.nes.scot.nhs.uk/education-and-training/bydiscipline/pharmacy/pre-registration-pharmacist-scheme.aspx. 12. NHS Pre-registration Trainee Pharmacist Training. Archived by Webcite ${ }^{\circledR}$ at http://www.webcitation.org/6a00K4ie2.

13. PHARMCAS: Pharmacy College Application Service. Archived by Webcite ${ }^{\circledR}$ at http://www.webcitation.org/6a00adBRI.

14. Duke LJ, Unterwagner L, Byrd DC. Establishment of a multistate experiential pharmacy program consortium. Am J Pharm Educ. 2008;72(3):Article 62.

15. McDuffie CH, Duke LJ, Stevenson TL, et al. Consortium-based approach to an online preceptor development program. Am J Pharm Educ. 2011;75(7):Article 135. 


\section{American Journal of Pharmaceutical Education 2016; 80 (9) Article 151.}

16. Speedie MK, Baldwin JN, Carter RA, et al. Cultivating 'habits of mind' in the scholarly pharmacy clinician: report of the 2011-12 Argus Commission. Am J Pharm Educ. 2012;76(6):Article S3. 17. Freml JM, Farris KB, Fang G, et al. Iowa's Priority's brown bag medication reviews: a comparison of pharmacy students and pharmacists. Am J Pharm Educ. 2004;68(2):Article 50.

18. Haggerty SA, Cerulli J, Zeolla MM, Cottrell JS, Weck MB, Faragon JJ. Community pharmacy target intervention program to improve aspirin use in persons with diabetes. $J$ Am Pharm Assoc. 2005;45(1):17-22.

19. Nuffer W, McCollum M, Ellis SL, Turner CJ. Further development of pharmacy student-facilitated diabetes management clinics. Am J Pharm Educ. 2012;76(3):Article 50.
20. Hata M, Klotz R, Sylvies R, et al. Medication therapy management services provided by student pharmacists. Am J Pharm Educ. 2012;76(3):Article 51.

21. Hardin HC, Hall AM, Roane TE, Mistry R. An advanced pharmacy practice experience in a student-staffed medication therapy management call center. Am J Pharm Educ. 2012;76(6):Article 110. 22. NHS National Services Scotland. NHS Smoking Cessation Services Report. http://www.isdscotland.org/Health-Topics/Public-Health/ Publications/2014-05-27/2014-05-27-SmokingCessation-Report.pdf. 23. NHS Scotland. The NHS Minor Ailment Service at your local pharmacy. http://www.gov.scot/Resource/Doc/362554/0122689.pdf 24. NHS inform. The NHS Chronic Medication Service at your local pharmacy. http://www.gov.scot/Resource/0043/00433677.pdf. 